\title{
Predictive Factors for Failed Endoscopic Retrograde Cholangiopancreatography
}

\author{
Hassan Abd El-Hafiez, Mohamed Abdel Rasheed, Mohamed Ismail Fadel* \\ Tropical Medicine Department, Al Azhar University
}

\begin{abstract}
Background: failure during cannulation renders the endoscopic retrograde cholangiopancreatography (ERCP) unsuccessful and gives rise to various consequences, including cholangitis and pancreatitis, which may require interventions, such as percutaneous transhepatic cholangiography (PTC) and surgery, with higher morbidities.
\end{abstract}

Aim of the Work: we aimed to establish predictive factors for ERCP failure.

Patients and Methods: a total of 103 ERCP procedures were done from October 2016 to October 2017 in the endoscopy unit at AL Hussein university hospital. Patients were divided according to ERCP results into 2 groups; group I consists of 93 cases of successful ERCP procedure (90.2\%) and group II consists of 10 cases of failed ERCP procedure (9.7\%). After clear written consent, full clinical, sonographic and laboratory evaluation were done for all patients.

Results: patients with history of previous abdominal surgery andlor CBD stricture had a significant higher rate of ERCP failure. Duodenal diverticula, papillary mass and gastric outlet obstruction were significantly higher in failed ERCP group.

Conclusion: any patient with history of previous abdominal surgery, CBD stricture and benign or malignant tumors should be investigated before ERCP with non-invasive image as magnetic resonant cholangiopancreatography (MRCP) or Endoscopic ultrasound (EUS).

Keyword: Endoscopic Retrograde Cholangiopancreatography, Magnetic Resonant Cholangiopancreatography and Endoscopic Ultrasound

\section{INTRODUCTION:}

Since its introduction in 1968, endoscopic retrograde cholangiopancreatography (ERCP) has become a commonly performed endoscopic procedure. The diagnostic and therapeutic utility of ERCP has been well demonstrated for a variety of disorders, including the management of biliary malignancies, and the evaluation and treatment of benign and malignant disease of the pancreas ${ }^{(1)}$.

Successful biliary therapy during endoscopic retrograde cholangio-pancreatography (ERCP) requires selective cannulation of the bile duct. Despite advances and new developments in endoscopic accessories such as catheters, guidewires and sphincterotomes, selective biliary cannulation fails in 5\%-15\% of cases, even in expert high-volume centers ${ }^{(2)}$.

Difficult biliary cannulation was defined as failure to achieve selective biliary access by wire-guided cannulation despite $5 \mathrm{~min}$ of attempted cannulation (cannultion time $>5 \mathrm{~min}$ ), papillary contacts $>5$ times, attempted unintentional pancreatic duct cannulation $\geq 3$ times, or hook-nose-shaped papilla (difficult type of cannulation) ${ }^{(2)}$.

\section{PATIENTS AND METHODS:}

This prospective study was carried out at AL Hussein University Hospital Endoscopy unit from October 2016 to October 2017. The examined patients were divided according to ERCP results into 2 groups; group I successful ERCP cases; and group II of failed ERCP cases.

All patients signed an informed written consent before the procedures, after receiving an explanation on the risks, benefits and alternatives of ERCP and associated therapeutic procedures. The study was approved by the Ethics Board of Al-Azhar University.

All patients were subjected to full history taking, full laboratory evaluation included; complete blood picture, prothrombin time and partial thromboplastin time, liver functions, renal functions and serum amylase, as well as 
abdominal ultrasound andlor abdominal CT or MRCP when needed.

ERCP was performed under general anesthesia with the patient in the left-lateral or semi prone position. All procedures were performed by standard videoduo-denoscopes (Fujinon ED-250 XT). Introduction and positioning of the endoscope followed by cannulation of the CBD with standard sphincterotomy, precut or balloon dilatation and contrast injection.

During the procedure, all endoscopic data were reported, and any adverse event or complications occurred were documented in an ERCP data sheet that was designed for all patients undergoing the procedure.

Data entry and statistical analysis were performed using the statistical package for social science, version 20. Independent -samples t-test of significance was used when comparing between tow means. $\mathrm{x}^{2}$-test of significance was used to compare proportion between tow qualitative parameters.

\section{RESULTS:}

The commonest indication was calcular obstructive jaundice in 93 cases $(90.2 \%)$ then malignant obstructive jaundice in 9 cases $(8.7 \%)$ with no significant differences between the studied groups.

There is no significant difference between the studied groups regarding, age and sex, laboratory values or sonographic findings

Patients with history of previous abdominal surgery andlor CBD stricture had a significant higher rate of ERCP failure.

Table 1: Endoscopic findings in the studied groups

\begin{tabular}{||l|c|c|c|c|c|c||}
\hline \multicolumn{1}{|c|}{} & \multicolumn{2}{c|}{ Group I } & \multicolumn{2}{c|}{ Group II } & \multicolumn{2}{c||}{} \\
\cline { 2 - 8 } & $\mathbf{N}$ & $\mathbf{\%}$ & $\mathbf{N}$ & $\mathbf{\%}$ & $\mathbf{X}^{\mathbf{2}}$ & P-value \\
\hline \hline Duodenal diverticula & 2 & 2.2 & 2 & 20.00 & 7.707 & $0.0055^{*}$ \\
\hline Papillary mass & 2 & 2.15 & 2 & 20.00 & 7.707 & $0.0055^{*}$ \\
\hline Duodenal ulcer & 2 & 2.2 & 1 & 10.00 & 1.96 & 0.16 \\
\hline Duodenal fistula & 1 & 1.08 & 0 & 0.00 & 1.870 & 0.172 \\
\hline Flat papilla & 3 & 3.23 & 1 & 10.00 & 0.037 & 0.848 \\
\hline Gastric outlet obstruction & 1 & 1.08 & 2 & 20.00 & 9.391 & $0.00218^{*}$ \\
\hline
\end{tabular}

Duodenal diverticula, papillary mass and gastric outlet obstruction were significantly higher in failed ERCP group.

Table 2: ERCP diagnostic and therapeutic findings in patients of group-I

\begin{tabular}{|l||c|c|c||c|}
\hline \multicolumn{1}{|c||}{ ERCP diagnosis } & \multicolumn{2}{c|}{ Group I } & \multirow{2}{*}{ Therapeutic maneuver } & N \\
\cline { 2 - 5 } Calcular & $\mathbf{N}$ & $\mathbf{\%}$ & $\begin{array}{c}\text { Stone extraction } \\
\text { Stent application } \\
\text { Lithotripsy }\end{array}$ & $\mathbf{7 3}$ \\
\hline \hline CBD stricture & 86 & 92.47 & Stenting & $\mathbf{3}$ \\
\hline Pancreatic mass & 2 & 2.15 & Stenting & 2 \\
\hline Papillary mass. & 3 & 3.23 & Stenting & 2 \\
\hline
\end{tabular}

Procedure done in group 1 was treatment of 86 cases of calcular obstruction ,73 of them by stone extraction, 10 cases with stenting and lithotripter was used in the remaining 3 cases. Stent was placed in 7 cases, 2 of stricture, 3 of pancreatic mass and 2 of papillary mass. 
Table 3: Endoscopic findings in failed ERCP group

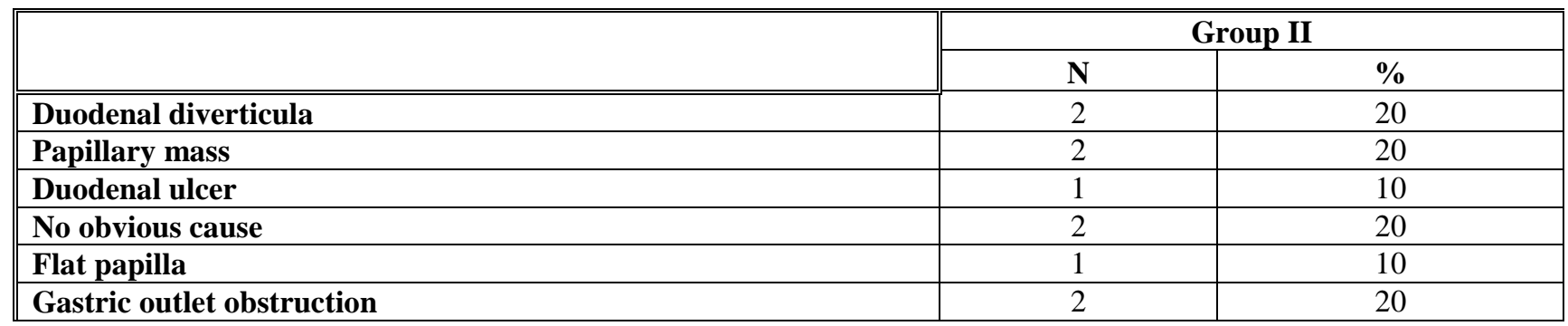

Failed cases of ERCP were 2 cases of duodenal diverticula, 2 cases of papillary mass, 1 case of duodenal ulcer, 1 case of flat papilla and 2 cases of gastric outlet obstruction and in 2 cases no obvious cause was detected.

\section{DISCUSSION:}

Yuichi et al. ${ }^{(3)}$ studied the ERCP success and failure rates and documented that age and sex have no significance value and the main indication for ERCP was choledocholithiasis.

In our study, the commonest indication for ERCP was calcular obstructive jaundice in 93 cases $(90.2 \%)$ then malignant obstructive jaundice in 9 cases $(8.7 \%)$ with no significant differences between the studied groups.

We agreed with Bruno et al. (4) who stated that, no differences were found regarding clinical presentation.

We found that previous abdominal surgery is a direct cause of failed ERCP.

It is the same as Choudari et al. ${ }^{(5)}$ who stated that, Adhesions due to previous upper abdominal surgery, gastrointestinal diversions, and gastrointestinal obstructions are also factors that affect the cannulation of the papilla during ERCP. Billroth I or II interventions, Roux-en-Y gastrojejunostomy, gastric outlet obstruction, and narrowing of the duodenum have been listed as reasons for ERCP failure.

We found that, patients with CBD stricture had a significant higher rate of ERCP failure.

Cases of malignant or benign pathologies that narrow or obstruct the gastrointestinal system, the cannulation success rate was low ${ }^{(6)}$.

We stated that, duodenal diverticula, papillary mass and gastric outlet obstruction were significantly increased the ERCP failure rate compared to patients with no such pathology.
In their published series, Fukatsu et al. ${ }^{(6)}$, Freeman and Guda ${ }^{(7)}$ showed that malignant biliary tract obstructions decrease the cannulation success rate during ERCP.

Also, narrowing of the duodenum have been listed as failure reasons in ERCP ${ }^{(\mathbf{8})}$.

\section{CONCLUSION :}

We concluded that, before ERCP procedure careful history taking and imaging evaluation could reduce failure rate, as altered anatomy from previous abdominal surgeries decrease the cannulation success rate. During the procedure benign or malignant gastrointestinal lesions that prevents the passage of the endoscope as gastric outlet obstruction may increase the failure rate. Duodenal diverticula and CBD stricture carried higher rates of ERCP failure.

So, any patient with history of previous abdominal surgery, CBD stricture and benign or malignant tumors should be investigated before ERCP with non-invasive image as magnetic resonant cholangiopancreatography (MRCP) or Endoscopic ultrasound (EUS).

\section{REFERENCES:}

1. Mallery JS, Baron TH, Dominitz JA et al. (2003): ASGE Standards of Practice Committee: complication of ERCP. Gastrointest Endosc., 57: 633 - 638.

2. Lee TH, Bang BW, Park SH, Jeong S, Lee DH and Kim SJ (2011): Precut fistulotomy for difficult biliary cannulation: is it a risky preference in 
relation to the experience of an endoscopist? Dig Dis Sci., 56: 1896-1903.

3. Yuichi T, Masatsugu N, Fumitaka N, Takahiro K, Eiichi $Y$ and Naotaka M (2018): Optimal timing for precutting in cases with difficult biliary cannulation. Endosc Int Open., 6(8): E1015-E1019.

4. Bruno M, Ribaldone D, Fasulo R, Gaia S, Marietti $M$ and Risso A (2018): Is there a link between periampullary diverticula and biliopancreatic disease? An EUS approach to answer the question. Dig Liver Dis., 50(9):925-930.

5. Choudari CP, Sherman S, Fogel EL et al. (2000): Success of ERCP at a referral center after a previously unsuccessful attempt. Gastrointest Endosc., 52: 478 83.
6. Fukatsu H, Kawamoto $H$, Kato $H$ et al. (2008): "Evaluation of needle knife precut papillotomy after unsuccessful biliary cannulation, especially with regard to postoperative anatomic factors," Surgical Endoscopy and Other Interventional Techniques, 22(3): 717-723.

7. Freeman ML and Guda NM (2005): ERCP cannulation: a review of reported technique, Gastrointestinal Endoscopy, 61: 113-125.

8. Sherman $S$ and Lehman GA (1990): Complications of endoscopic retrograde cholangiopancreatography and endoscopic sphincterotomy. In: Barkin J, O'Phelan CA, eds. Advanced therapeutic endoscopy. New York: Raven press. 